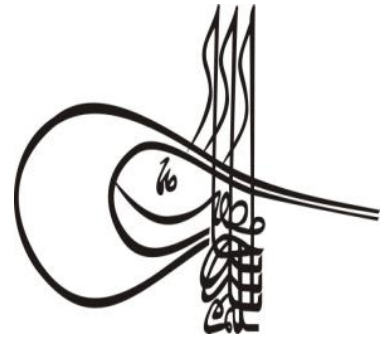

Received/Geliș: 15.09.2019
Turkish Studies

\section{Language and Literature}

Volume 14 Issue 4, 2019, p. 1971-1988

DOI: 10.29228/TurkishStudies.37038

ISSN: 2667-5641

Skopje/MACEDONIA-Ankara/TURKEY

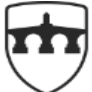

INTERNATIONAL BALKAN UNIVERSITY

EXCELLENCE FOR THE FUTUR IBU.EDU.MK

Research Article / Araștırma Makalesi

Article Info/Makale Bilgisi

\Accepted/Kabul: 20.12 .2019

Gor Report Dates/Rapor Tarihleri: Referee 1 (07.10.2019)-Referee 2 (12.10.2019)

This article was checked by iThenticate.

\title{
GELENEĞİN İCADI BAĞLAMINDA NASREDDİN HOCA KARİKATÜRLERİ
}

\author{
Hasan KIZILDA $\check{G}^{*}$
}

öz

Gelenek, bir milletin tarih sahnesine çıktığı ilk andan başlayarak tarihî, içtimaî birikimler ve kültürel unsurlar çerçevesinde oluşturduğu, birtakım tekrar, sembol ve uygulamalara dayanan toplumsal kabullerdir. Bu yönüyle toplumu kușatır ve topluluğun bütün unsurları üzerinde etki sahibidir. Toplumsal kabuller, geleneğin bağlayıcılığı neticesinde belirlenir. Gelenek, toplumun mazisiyle bugününü, tarihî birikimi kullanmak suretiyle harmanlar ve nesilden nesile aktarım yoluyla geleceğe uzanır. Bu sebeple kültürün aktarıcısı gelenektir.

Teknik ve teknolojik gelişmeler, zamanla, geleneği de etkilemektedir. Gelenek, ihtiyaçlar ve çağın şartları çerçevesinde değişir, dönüşür ve güncele uyarlanır. Değișim, geleneğin yeni unsurlarla bütünleşmesi yoluyla meydana gelmekteyken; dönüşüm ve uyarlanma, maziye ait unsurlardan esinlenmek yoluyla yeni kabul, uygulama ve ürünlerin ortaya çıkarılması şeklinde gerçekleşir. Bu süreçler dışında, gelenek yeniden icat edilerek de çağa ayak uydurur. "İcat edilmiş gelenek" veya "geleneğin icadı", geçmişin bağlarına dayanan yeni bir geleneksel yorum ve yer yer tamamen yeni bir gelenek meydana getirir. $\mathrm{Bu}$ bakımdan icat edilmiş gelenek, küreselleşen dünyada kültürel unsurların yaşatılması ve geleceğe aktarılmasında önemli bir rol üstlenir.

Nasreddin Hoca; hazır cevaplığı, zekâsı, olaylar karşısındaki tutumu ve dünya görüşüyle Türk kültürünün en önemli yapıtaşlarından birisidir. Geçmişten günümüze, ismi çevresinde anlatılagelen fikralar, Türk toplumunun mizah ve eğlenme ihtiyaçlarına cevap vermekle beraber, didaktik birer anlatı olma özelliği de taşımaktadır. Bu sebeple "Nasreddin Hoca" ismi, kolektif bellekte yaşayan fikraları da aşarak bütün sanat eserlerinde kendine yer 
bulmayı başarmıştır. Gelenekte kendi başına yaşayabilme başarısı gösteren Nasreddin Hoca tipi; tiyatro, sinema, öykü ve roman gibi edebi ürünlerde sıklıkla kullanılmasının yanı sıra karikatür sanatında da kendine yer bulmuş ve birçok karikatüre konu edilmiştir. Mizahî yönü ve toplumu kuşatıcılığının da yardımıyla karikatürlerde önemli bir tip haline gelmiştir. Anakronik öğeler ve dönüştürümlerin kullanımıyla modern dünyaya taşınması, fikralarının günümüz mizah anlayışılla yeniden değerlendirilmesi, Nasreddin Hoca çerçevesinde yeni bir gelenek "icat" etmiştir. İcat edilmiş bu gelenek sonucunda Hoca'nın ismi etrafinda anlatılan yeni fikralar meydana gelmiştir. Çünkü karikatürlerde Nasreddin Hoca fikralarına yapılan her bir gönderme, ekleme çıkarma, dönüştürüm, yeni, daha önce anlatılmamış bir fikra yaratmaktadir.

$\mathrm{Bu}$ çalışmada, farklı mizah dergilerinde yayınlanan Nasreddin Hoca karikatürleri, geleneğin icadı bağlamında incelenecektir. Nasreddin Hoca'ya atfedilen hangi fikraların ne șekilde kullanıldığı, ne gibi anakronik ve edebi dönüştürümler yapıldığg, fikralardan hareketle yeniden yaratımın ne şekilde gerçekleştirildiği ve kurgunun bozularak yeni formlara ne şekilde büründürüldüğü incelenecektir. Elde edilen bulgulardan hareketle, Nasreddin Hoca etrafinda icat edilen yeni geleneğin vasıfları tartışılacaktır.

Anahtar Kelimeler: Nasreddin Hoca, geleneğin icad1, anakronizm, karikatür, dönüştürüm, yeniden yaratım

\title{
NASREDDIN HODJA CARICATURES IN THE CONTEXT OF THE INVENTION OF TRADITION
}

\begin{abstract}
Tradition is a social acceptance based on several repetitions, symbols, and practices that a nation has formed within the framework of historical, social accumulations and cultural elements from the moment it first appeared on the stage of history. In this aspect, it surrounds the community and influences all elements of the community. Social admissions are determined by the binding of tradition. Tradition blends the past and present of society and extends to the future through generation to generation transmission. For this reason, tradition is the transponder of culture.

Technical and technological developments, over time, also affect tradition. Tradition changes, changes and adapts to the present within the framework of needs and conditions of the age. While change occurs through the integration of tradition with new elements, transformation and adaptation take place in the form of new acceptance, practices and products through inspiration from the elements of the past. Apart from these processes, tradition is re-invented and keeps up with the times. "The invented tradition" or "the invention of tradition" creates a new traditional interpretation based on the bonds of the past and, in places, a completely new tradition. In this respect, the invented tradition plays an important role in sustaining and transferring cultural elements into the future in the globalized world.
\end{abstract}


Nasreddin Hodja is one of the most important building blocks of Turkish culture with his ready-to-answer, intelligence, attitude towards events and world view. From the past to the present, the jokes that are narrated around the name of Nasreddin Hodja respond to the needs of Turkish society for humor and fun, but they are also didactic narratives. For this reason, the name "Nasreddin Hodja" has managed to find its place in all works of art by transcending the jokes that live in the collective memory. Nasreddin Hodja type, who is successful in living on his own in the tradition, has found a place in the art of caricature as well as being frequently used in literary products such as theatre, cinema, short stories and novels and has been the subject of many caricatures. With the help of his humorous direction and his encirclement of society, Hodja became an important type in cartoons. A new tradition has been "invented" within the framework of Nasreddin Hodja, to convey his jokes to the modern world through the use of anachronistic elements and transformations, to reassess his jokes with the modern sense of humor. As a result of this invented tradition, new jokes around Hodja's name have emerged. Because every reference to Nasreddin Hodja jokes in cartoons, adding, removing, converting, creates a new, previously untold joke.

In this study, the caricatures of Nasreddin Hodja published in different humor magazines will be examined in the context of "the invention of tradition". It will be examined how the jokes attributed to Nasreddin Hoca were used, what anachronistic and literary transformations were made, how the re-creation was performed based on the jokes, and how the fiction was distorted and taken into new forms. Based on the findings, the characteristics of the new tradition invented around Nasreddin Hodja will be discussed.

\section{STRUCTURED ABSTRACT}

Laugh is one of the most interesting aspects of human nature. It contains peace and happiness. A true smile has the power to free a man from all his troubles and worries. For this reason, the laugh is a barrier that maintains the mental balance of man in the face of the world's distortions, evils, chaos and difficulties, and is the key to immortality, albeit for a short time, against the reality of mortality. Laughing is an act as old as human history and it has a huge impact on human behavior and culture. With its aesthetic and relaxing side, it gives flexibility to all whatever is in the name of strictness in social memory. Thus, it makes social coexistence and cohesion possible.

Today, humor magazines are one of the main media in which the elements of humor are reflected in print. In these magazines, cartoonists create unique laugh elements by feeding on culture. Thus they unite society in the context of the act of laughing. The illustrators feed on oral culture as well as written culture and transform these literary genres with humorous aspects of folk culture elements. In this way, elements of folk culture are updated and transformed and culture is provided without interruption. On the other hand, the cartoon, appears in a struggle for existence, in which the individual interacts with all the elements of life by putting the elements of laughing at its foundation. Man criticizes, refreshes, updates, relieves anxiety, relaxes,

Turkish Studies - Language and Literature

Volume 14 Issue 4, 2019 
washes and reestablishes himself with caricature. Thus, caricature creates a healthier individual and community structure by distributing social problems, distinctions and troubles. It plays a major role in the progress and development of society through the sense of comfort and joy it creates in the collective consciousness.

Nasreddin Hodja has always been one of the first names of Turkish humor and caricature that comes to mind. The philosophical depth in the humor elements that developed around his name; the fact that his jokes are known to almost all segments of society and have a reputation that transcends boundaries; the fact that his jokes are appropriate and adaptable to each period by encircling the age is one of the main reasons for this interest and fame. In this respect, Nasreddin Hodja has been the subject of other works of art such as caricature, theatre and cinema. Nasreddin Hodja jokes were moved to a new location due to changing social conditions, production-consumption and entertainment culture.

Living in the past as the most important representative of Turkish humor, intelligence and quick answer in the collective memory, Hodja has today spread to the masses through the possibilities of the printing press and has started to find a place in many media with today's technological possibilities. However, the loss of the traditional narrative environment, the weakening of social/individual communication as a result of the conditions of the age, has had negative consequences for Nasreddin Hodja's jokes, as have other oral elements. At this point, books, cartoons, films, and theatre texts that are the subject of Nasreddin Hodja jokes were put forward and the jokes attributed to Hodja were tried to be brought together with the society. Besides the artistic activities mentioned, the relationship between Nasreddin Hodja and caricature is very important. While other art fields mostly treat the jokes attributed to Hoca as they are, cartoonists insert and change and transform the jokes into different forms, relationships of event, time and space. Thus, a new tradition is invented around the jokes of Nasreddin Hodja in conscious or unconscious ways, and the jokes, whose narrative environment has been weakened, are delivered to large sections of society through caricatures.

Nasreddin Hodja's wisdom and world-wide reputation, which can reach beyond his time and not only his era or society, offer inclusiveness for the present and even for the future, and guide humanity. Today, cartoonists also reflect Nasreddin Hoca, one of the most important representatives of Turkish humor, in their works with great importance and often create new Nasreddin Hoca jokes in today's world.

In this study, 26 caricatures emerged from the pen of many cartoonists such as Özer Aydogan, Serkan Altuniğne, Selçuk Erdem and Gürcan Yurt, which were created based on jokes of Nasreddin Hodja, were examined. The study made use of the "invention of tradition" theory by Eric Hobsbawm and Terence Ranger.

In the jokes, the invention of tradition by means of anachronism, the invention of tradition by means of continuing the jokes, the invention of tradition by means of changing the course of events of the

\section{Turkish Studies - Language and Literature}

Volume 14 Issue 4, 2019 
clause, caricatures emphasizing the power of tradition were identified/detected.

According to the data found, the tradition of jokes developed around the Hodja is remarkable in that it is subjected to the process of "inventing the tradition" by cartoonists today to create new jokes, influence new generations and draw the image of a new Nasreddin Hodja.

Cartoons have changed and transformed the jokes attributed to Hodja, creating new humorous elements and interpretations, and have introduced the Hodja's typification in the minds of modern-day people into new images. The new state of the jokes attributed to Hoca in the cartoons or the cartoons inspired by these jokes in a way created a "living jokes tradition" around Nasreddin Hodja, but created a "new oral culture" that will attract the attention of new generations. According to the results obtained, as a result of the cartoonists ' artistic attitudes and caricatures, Nasreddin Hoca created a new tradition, both coming from the tradition and containing the trace of the tradition. These Nasreddin Hodja cartoons occupy an important place in today's visual age. 21 . in the century, New Nasreddin Hodja jokes were created. These jokes create a new era of oral culture.

It is seen that cartoons and new jokes to be created through the processing of the jokes attributed to Hodja supported the tradition, brought it up again and changed it and invented the tradition. In this respect, the analysis of these cartoons will give important answers about the sociological, cultural and new traditional life of today. Changing and transforming elements of culture through cartoons are signs of a transition to a new phase in the cultural context. This new phase, to be realized with the invention of tradition, must be carefully monitored and examined by folklorists and other scientists.

Keywords: Nasreddin Hodja, the invention of tradition, anachronism, caricature, transformation, re-creation

\section{Giriş}

Gülme, insan tabiatının en ilginç yanlarından birisidir. Bir yanıyla huzuru, bir yanıyla mutluluğu içerisinde barındırır. Gerçek bir gülüş, beraberinde getirdiği neşe ve huzurun yanı sıra insanı bütün dertlerinden ve kaygılarından azade etme gücüne sahiptir. Bu sebeple gülme, dünyanın çarpıklıkları, kötülükleri, kaosu ve zorlukları karşısında insanın aklî dengesini muhafaza eden bir bariyer, fanilik gerçeğine karşı kısa süreliğine de olsa ölümsüzlüğün anahtarıdır. Arthur Koestler'e göre kahkaha, ancak aklî duyguların zorlamalarından bir ölçüde kurtulmuş ve kendi duygularını fazlalık olarak algılayan bir yaratıkta oluşabilecek lüks bir tepke ${ }^{1}$ dir (1997: 106). Bu yönüyle gülme, insanın en özgür davranışlarından birisidir. Hem istemeden yapılan bir davranış olması, hem de insanı bütün dünyevî sıkıntılardan kurtarıyor oluşu, gülmeyi özgürlüğün anahtarı haline getirmektedir.

Barry Sanders'e göre gülme, o kadar temel, evrensel ve yararlı bir davranıştır ki, herhangi bir yerde ya da herhangi bir zamanda gülmeyen bir insan topluluğunu düşünebilmek mümkün değildir (2001: 24). Henry Bergson, gülmenin, yarattı̆̆ı korkuyla acayiplikleri, sıra dışılıkları bastırıp kendini yalıtma ve uykuya dalma eğilimindeki kimi ikincil faaliyetleri sürekli uyanık ve birbiriyle temas

\footnotetext{
${ }^{1}$ Tepke, önceden kestirilebilir, kalıplaşmış davranış örnekleridir. İstemeden veya otomatik olarak yapılan davranışlar olarak nitelendirilebilir. Gülme bir tepkedir. Bu yönüyle reflekslerden ayrılır. Detaylı bilgi için bkz. Koestler (1997).
}

\section{Turkish Studies - Language and Literature}

Volume 14 Issue 4, 2019 
halinde tutma ve nihayet, toplumsal bünyenin sathında mekanik katılık adına ne varsa hepsine esneklik kazandırma gücü olduğunu belirtir. Dolayısıyla gülme sadece estetiği ilgilendiren bir konu değildir. Zira "gülme", herkesin mükemmelleşmesi gibi faydalı bir amaç gözetir. Ama "gülme"de yine de estetik bir yan vardır çünkü gülünç, tam da birey ve toplum kendi devamını sağlama endişesinden kurtulduğunda ve kendine birer sanat eseriymiş gibi muamele etmeye başladığında doğar (2014: 15).

Gülme, insanlık tarihi kadar eski bir eylem olmakla beraber insan davranışları ve kültür üzerinde büyük bir etkiye sahiptir. Estetik ve rahatlatıcı yanıyla, toplumsal bellekte katılık namına ne varsa hepsine esneklik kazandırır. Böylece toplumsal birlikteliği ve kaynaşmayı mümkün kılar.

Günümüzde güldürü öğelerinin basılı halde yansitıldığı temel mecralardan biri de mizah dergileridir. Bu dergilerde çizerler, kültürden beslenmek suretiyle özgün güldürü öğeleri oluşturur ve böylelikle gülme eylemi bağlamında toplumda bütünleşmeye vesile olurlar. Çizerler, yazılı kültür kadar sözlü kültürden de beslenir ve halk kültürü öğelerinin mizahî yanlarıyla bu edebî türleri dönüştürür. Bu yolla halk kültürü unsurları güncellenip, dönüştürülerek kültürde kesintisizlik sağlanır. Karikatür ise gülme unsurlarını temeline koyarak bireyin, hayatın bütün unsurlarıyla etkileşimli olarak giriştiği bir varoluş mücadelesinde ortaya çıkar. Karikatürle birey, eleştirir, yeniler, günceller, kaygıları dindirir, kendini rahatlatır, yıkar ve yeniden kurar... Böylece karikatür, toplumsal sorunları, ayrımları, dertleri, bireyin iç yaşantısındaki sıkıntıları dağıtarak daha sağlıklı bir birey ve toplum yapısı oluşturur. Kolektif bilinçte yarattığı rahatlık ve neşe hissiyle toplumun ilerlemesi ve gelişmesinde büyük bir rol oynar (Kızıldağ, 2018: 269-270).

$\mathrm{Bu}$ çalışmada Selçuk Erdem, Özer Aydoğan, Serkan Altuniğne, Yiğit Özgür gibi karikatür sanatçılarının çizdiği Nasreddin Hoca karikatürlerinden 26'sı seçilerek geleneğin icadı bağlamında incelenmiştir.

\section{Karikatür ve Nasreddin Hoca}

Türkiye'de karikatür ve karikatür dergiciliği ${ }^{2}$ mizahî edebiyatın gelişmesiyle başlar. Nebi Özdemir'e göre Türk yazılı mizah edebiyatı, Teodor Kasap, Mehmet (Çaylak) Tevfik ve Ali Fuad öncülüğünde; Tanzimat'ın ilanından sonraki dönemde 1869'da Letaif-i Âsâr ve Diyojen'le başlamıştır. "Leman, Penguen, Uykusuz, Gırgır" gibi dergilere kadar ciddî bir mizah dergiciliği birikimine sahip olan mizah basını, Türk medyasının en erken gelişen alanlarından biridir. Mizah basını ya da basında mizahî unsurların kullanılması, bir taraftan yazılı medyanın, dolayısıyla yazılı Türk mizah edebiyatının gelişmesini, diğer taraftan da Türk mizah kültürünün bütüncül olarak değerlendirilmesini, dahası ortak hedef olan toplumun yazılı kültür temelinde yeniden kurgulanmasını ve işletilmesini sağlamıştır (2012: 73-74).

Nasreddin Hoca, her zaman Türk mizahı ve karikatürünün akla gelen ilk isimlerinden biri olmuştur. Adı etrafında gelişen güldürü öğelerindeki felsefî̀ derinlik; fikralarının toplumun neredeyse bütün kesimleri tarafından bilinmesi ve sınırları aşan bir şöhrete sahip olması, fikralarının çağı kuşatarak her devre uygun ve uyarlanabilir olması, bu ilginin ve ünün temel sebeplerindendir. $\mathrm{Bu}$ yönüyle Nasreddin Hoca tiyatro ve sinema gibi diğer sanat eserleri ${ }^{3}$ nin de konusu olmuştur.

\footnotetext{
${ }^{2}$ Türkiye'de karikatür geleneği ve karikatür dergiciliği hakkında detaylı bilgi için bkz. Öngören, Ferit (1998). Cumhuriyetin 75. Yılında Türk Mizahı ve Hicvi. İstanbul: İş Bankası Kültür Yay., Balcıoğlu, Semih (1976). 50 yılın Türk Mizah ve Karikatürü. İstanbul: Türkiye İş Bankası Kültür Yay.

${ }^{3}$ Nasreddin Hoca hakkında çekilmiş, Türkiye, Sovyetler Birliği, Bulgaristan ve İran yapımı filmler için bkz. Nastradin Hoca i Hitar Petar (1939), Nasreddin Hoca Dügünde (1943), Nasreddin v Buhare (1943), Nasreddin Hoca ve Timurlenk (1954), Nasreddin Hoca $(1954,1960,1965)$, Molla Nasreddin (1953, 1957), Nasreddin v Hocente (1959), 12 mogil Hoci Nasreddina (1966), Vozvraşteniye Hoci Nasreddina (1989); Tiyatro oyunları için bkz. Nasreddin Hoca Yollarda, Tiyatro Evi (2015), Nasreddin Hoca, Mersin Devlet Opera ve Balesi (2016), Nasreddin Hoca Bir Gün, Ankara Devlet Tiyatrosu (2016), Nasreddin Hoca Gide Gide, Tiyatro Evi (2017), Nasreddin Hoca Geliyor, Tiyatro Anadolu (2018), Nasreddin Hoca, Semaver Kumpanya (2018) ve diğerleri...
}

Turkish Studies - Language and Literature

Volume 14 Issue 4, 2019 
Nasreddin Hoca fikralarının sözlü kültür ortamından yazılı kültür ortamına taşınmasıyla beraber, bir taraftan sinema, tiyatro, çizgi sinema gibi alanlarda kullanılmaya başlanırken, diğer taraftan da karikatür gibi, az sözle çok şey anlatmaya dayalı bir tür içerisinde kendisine yer bulmuştur. Karikatürlerde Nasreddin Hoca tipinin ve fikralarının kullanımı oldukça yaygın bir durumdur. 1969 yılında Türkiye'de kurulan Karikatürcüler Derneği (The Association of Cartoonists)'nin düzenlediği "Uluslararası Nasreddin Hoca Karikatür Yarışması"”ın 39 yıldır; Azerbaycan'da, Azerbaycan Cumhuriyeti Kültür ve Turizm Bakanlığı, Azerbaycan Ressamlar Birliği ve Uluslararası Karikatüristler Teşkilatları Federasyonu'nun birlikte düzenlediği "Molla Nasreddin Uluslararası Karikatür Yarışmass" "nın 9 yıldır yapılıyor olması, Nasreddin Hoca ve karikatür ilişkisini göstermek bakımından önemlidir. 2016 yılında Ukrayna'da Ukrayna Karikatürcüler Birliği (Ukraine Cartoonist's Association) tarafindan düzenlenen "International Cartoon Exhibition of Nasredin Hodja Figures", isimli sergi de yukarıdaki bahse örnek olarak verilebilir. Bunun dışında Türkiye'de yayınlanan mizah dergilerinin neredeyse tamamında Nasreddin Hoca karikatürleri görmek mümkündür.

M. Fuat Köprülü, Nasreddin Hoca'ya isnat edilen görünüşte basit ancak derin bir hayat tecrübesi barındıran sözlerin halk arasında ağızdan ağza dolaşmakta olduğunu söylerken, Hoca'nın, Türklerin yanı sıra birçok milletlerin hayatında önemli bir yere sahip olduğunu belirtmektedir (2004: 19-20). Saim Sakaoğlu ve A. Berat Alptekin'e göre Hoca'nın toplum tarafindan bu denli sevilmesi onun halktan biri oluşu nedeniyledir. Belirli bir bölgeden ziyade, geneli temsil eden Nasreddin Hoca, halkın bütün sorun, arzu ve isteğinin dile dökülmüş, nükteli ve gülümseten halidir (2014: 65).

Nasreddin Hoca'nın karikatürlerde bu kadar sık ele alınıyor oluşu, kendisi hakkındaki anlatıların güncelliği ve çağı kuşatıyor oluşuyla ilgili olmalıdır. Nasreddin Hoca'ya atfedilen fikralardaki didaktik unsurların evrensel ${ }^{7}$ liği de karikatürlere malzeme edilmesinde önemli bir role sahiptir. Nasreddin Hoca, ironik yaşamda sonsuza yürüyen bir kahraman ${ }^{8}$ dır. Boratav'a göre, Nasreddin Hoca fikralarının son dönüşüm aşaması, sanatçıların fikralara bilerek yeni biçimler vermek ve yeni yorumlar yüklemek suretiyle Hoca'yı günümüzde yaşatmaktır. Nasreddin Hoca anlatılarının bu son aşamasındaki biçimleriyle de giderek sözlü geleneği etkileyeceğini unutmamak gerekir (2007: 48).

\section{Geleneğin İcadı, Nasreddin Hoca Fıkra ve Karikatürleri}

İcat edilmiş gelenek, alenen ya da zımnen kabul görmüş kurallarca yönlendirilen ve bir ritüel ya da sembolik bir özellik sergileyen, geçmişle doğal bir süreklilik anıştırır şekilde tekrarlara dayanarak belli değerler veya davranış normları aşılamaya çalışan bir pratikler kümesidir. Gelenekler icat etmek, geçmişe referansla belirginlik kazanan özünde bir formelleştirme ve rutinleştirme sürecidir (Hobsbawm ve Ranger, 2006: 2-5).

İcat edilmiş geleneği şu şekilde izah etmek mümkündür:

Geçmişten ilham almak suretiyle ortaya konan, bağlayıcı ve kuşatıcılık vasfina sahip, birtakım kabuller meydana getiren, zamanla yeni nesillere aktarılan bilgi, ritüel, yapı veya kurumlar geleneğin icadına örnek olarak verilebilir. Geçmişten alınan bir tema veya unsurun üzerine inşa edilen bu gelenekler, daha çok gerçek geleneklerin icra ortamının zayıfladığı ve kaybolduğu modern dönem toplumlarında yaygındır. Örneğin, etki seviyesi yüksek toplumsal bir olayın, mazideki muadilleriyle ilintilenerek geleceğe aktarılması veya inşa edilen kurum veya yapıların eskiye gönderme yapacak biçimde tasarlanması icat edilen gelenek olarak kabul edilebilir. İcat edilen bu gelenekler, zamanla

\footnotetext{
${ }^{4}$ Detaylı bilgi için bkz. https://www.karikaturculerdernegi.com

${ }^{5}$ Detaylı bilgi için bkz. https://cartooncolors.blogspot.com

${ }^{6}$ Detaylı bilgi için bkz. http://cwn-news.com

7 Nasreddin Hoca'nın Türk coğrafyaları ve dünyanın diğer ülkelerindeki yeri, önemi ve isimleri hakkında bilgi için bkz. (Sakaoğlu ve Alptekin, 2014: 90-129), (Türkmen, 2013: 11-19).

${ }^{8}$ Bkz. Şenocak, Ebru (2017). İronik Yaşamda Sonsuza Yürüyen Kahraman Nasreddin Hoca. Ankara: Akçağ Basım Yayım.
} 
kurumsallaşarak gerçek gelenekler haline gelebilir. Örneğin Türkiye Cumhuriyeti Cumhurbaşkanlığ forsunda yer alan on altı yıldız, ezelden beri mevcut değilken, tarihin nispeten yakın bir döneminden itibaren Türk devlet geleneğinin eskiliğine ve kutsiyetine atıfta bulunmak adına eklenmiş ve onlarca y1llık bir gelenek haline gelmiştir ${ }^{9}$. İnşa edilen kamu binalarının Selçuklu ve Osmanlı izleri taşıması da bu şekildedir. Geçmişe atıfla ortaya konan bütün eserlerde bir süreklilik izlenimi ortaya konulmaktadır. Böylece gelenek, "icat” edilmektedir.

İcat edilmiş geleneklerin gerçek geleneklerden ayrılan en önemli yönü zihniyet meselesidir. Geçmişten ilham alınan unsurlar, günün düşünce yapısıyla yeniden üretilir. Bu yeniden üretme sürecinde çağıın gereklerine veya üretenin dünya görüşüne uygun ekleme çıkarmalar ve dönüştürmeler yapılır. İcat edilmiş gelenekler geçmişteki esin kaynaklarından izler taşısa da bazı durumlarda tamamen bir "yeniden yaratım" söz konusudur.

Benzer durumlar sanat eserlerinde de geçerlidir. Resim, müzik, heykel gibi birçok sanat dalında eskinin ihtişamından, geçmişteki kahramanlardan veya olaylardan esinlenen eserler üretilmektedir. Ancak bilinçli bir şekilde geçmişten beslenen bu ürünler yeniden yaratım yoluyla yeni bir geleneği icat etmekte ve bu gelenek aynı konudaki gerçek gelenekle eşgüdümlü olarak hayatiyetini devam ettirmektedir. Zamanla, eski geleneğin gücünün iyice zayıflaması sonucunda, icat edilmiş gelenek öne çıkmakta ve geçmişin izlerini belirli oranda barındırmak suretiyle gerçek bir gelenek haline gelmektedir.

Nasreddin Hoca fikraları da değişen toplumsal şartlar, üretim-tüketim ve eğlence kültürü nedeniyle yeni bir konuma taşınmıştır. Geçmişte, kolektif bellekte bütün canlılığıyla Türk mizahının, zekâsının ve hazır cevaplığının en önemli temsilcisi olarak şifahî bağlamda yaşayan Hoca, gelenekselşifahî anlatı ortamının ortadan kalkmaya başlamasıyla beraber matbaanın imkânları üzerinden kitlelere yayılmış ve günümüz teknolojik imkânlarıyla birçok mecrada kendine yer bulmaya başlamıştır. Bununla beraber, geleneksel anlatı ortamının kaybolması, toplumsal/bireysel iletişimlerin, çağın şartları neticesinde zayıflaması, diğer şifahî unsurlar gibi, "dil"de yaşayan Nasreddin Hoca fikraları için de olumsuz sonuçlar doğurmuştur. Bu noktada, Nasreddin Hoca fikralarını konu edinen kitaplar, çizgi filmler, filmler ve tiyatro oyunları ortaya konulmuş ve Hoca'ya isnat edilen fikralar toplumla buluşturulmaya çalışılmıştır. Bahsi geçen sanatsal faaliyetlerin yanı sıra Nasreddin Hoca ve karikatür ilişkisi de oldukça önemlidir. Diğer sanat verimleri çoğunlukla Hoca'ya atfedilen fikraları olduğu gibi ele almaktayken, karikatüristler, fikraları farklı formlara, olay, zaman ve mekân ilişkilerine sokmakta ve değiştirip, dönüştürmektedir. Böylelikle bilinçli veya bilinçsiz şekillerde Nasreddin Hoca fikraları çevresinde yeni bir gelenek icat edilmekte, anlatı ortamı zayıflamıs olan fıkralar, karikatürler aracılığıyla toplumun geniş kesimleriyle buluşturulmaktadır.

Nasreddin Hoca fikralarının karikatürlerde kullanılmasıyla gelenek yeniden icat edilmektedir. Yukarıda Boratav'ın da belirttiği gibi, Hoca ile ilgili anlatıların yorumlanarak ve dönüştürülerek karikatürlerde kullanılması, karikatüristlerin bakış açısından yeni fikraların doğmasına kapı açmakla beraber, toplumda karşlık bulan bu karikatürlerdeki anlatı ve tiplemeler basılı görsellerden hareketle günümüz sözlü kültürünün oluşmasını sağlamaktadır.

\footnotetext{
${ }^{9}$ H. Nihal Atsız, Cumhurbaşkanlığı Forsu'nda yer alan 16 yıldızın Türkiye Cumhuriyeti’nden önce kurulmuş olan Türk devletlerini sembolize ettiği fikrine ve bahsi geçen bu devletlere isnat edilen bayraklara şiddetle karşı çıkmış ve bunların birer uydurma/su götürür iddialar olduğunu ileri sürmüştür (2014: 62-68). Atsız’nn bu görüşleri, bahsi geçen uygulamanın icat edilmiş bir gelenek olduğu fikrini destekler niteliktedir. Detaylı bilgi için bkz. Atsız, H. Nihal (2014). Türk Tarihinde Meseleler. Ankara: Ötüken Neşriyat.
} 


\section{Anakronizm Vasıtasıyla Geleneğin İcadı}

Batılı kaynaklarda zaman veya mekân ile alakalı sıçramalar "anakroni ${ }^{10}$ ", doğu ve özellikle İslamiyet kaynaklı anlatılarda "tayy-i zaman ve tayy-i mekân" olarak adlandırılmıştır. Edebi eser ve anlatılardaki anakroni, bir olayın veya kahramanın, zaman diliminde ileriye veya geriye sıçrayışı şeklinde gerçekleşmektedir. Zaman dilimini belirli aralıklarla büyütmek ve küçültmek mümkündür. Eserlerde olaylar, bir noktada kesilerek geçmişe dönülebilir. Hayali veya fiziki olarak ileriye sarılabilir (Kızıldağ, 2016: 451). Zamandaki kronolojinin bozulmas1, Nasreddin Hoca ile ilgili karikatürlerle sıklıkla kullanılmıştır. Karikatür 1'de Hoca fizikî olarak Cem Yılmaz'a benzetilmiştir. Bir stand-up gösterisi içerisinde karikatürize edilen Hoca, kolektif bellekte yer etmiş olan "Nasreddin Hoca'nın mizah anlayışı" bağlamında günümüz komedyenlerinden Cem Yılmazla özdeşleştirilmiştir. Bilinçli olarak yapılan bu anakronizm yoluyla Hoca, fizikî değişiklikler ve sahnede bir gösteri icra ederken tasvir edilerek günümüze taşınmış, diğer taraftan Cem Yılmaz, Hoca'nın suretiyle özdeşleştirilerek geçmişe götürülmüştür.

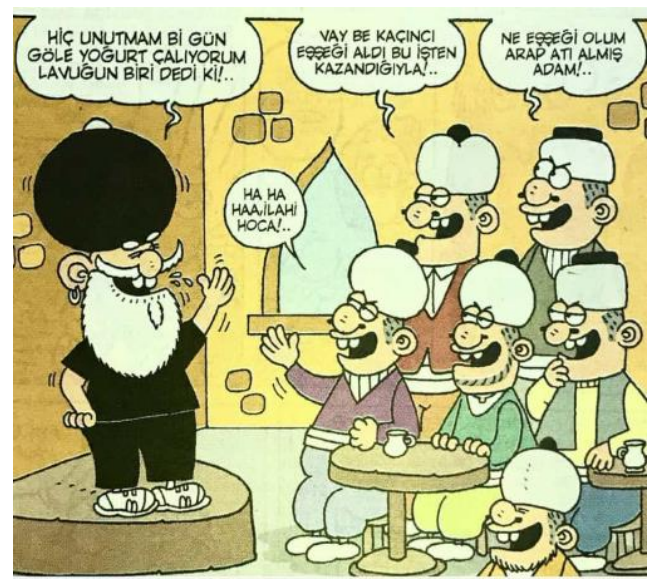

Karikatür 1

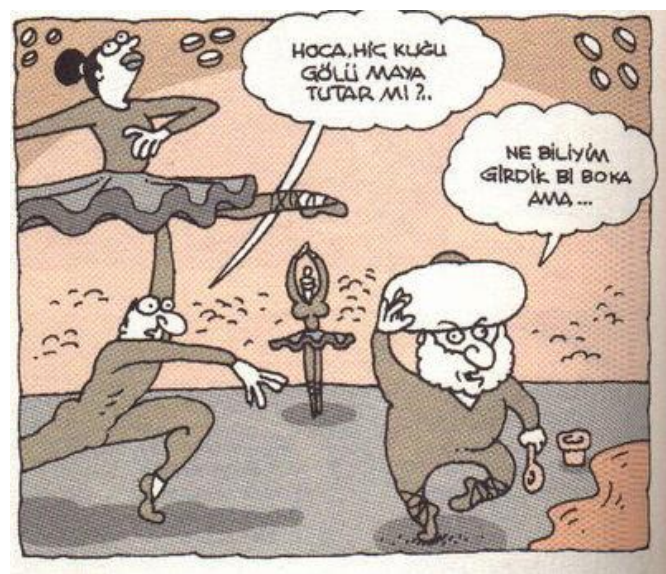

Karikatür 2

Karikatür 2'deki durum da Nasreddin Hoca'ya isnat edilen "Ya Tutarsa? (Sakaoğlu ve Alptekin, 2014: 232-233)" fikrasının modern çağa, ironi unsurları kullanılarak uyarlanmış halidir.

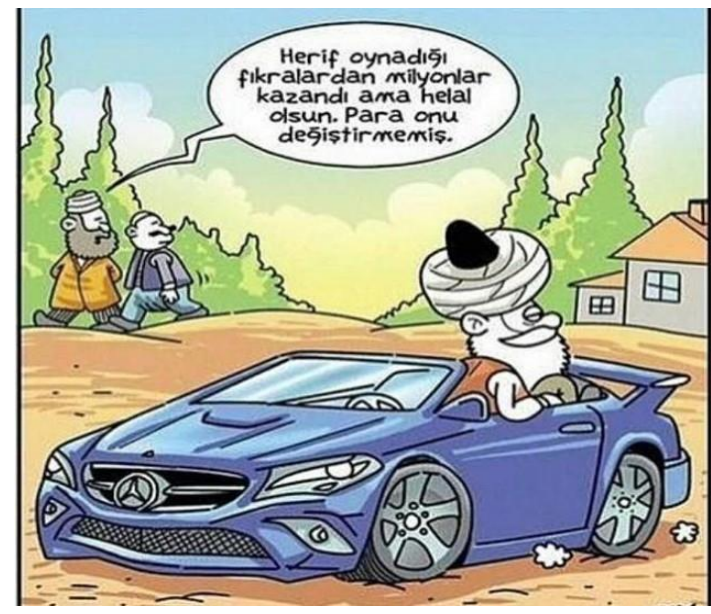

Karikatür 3

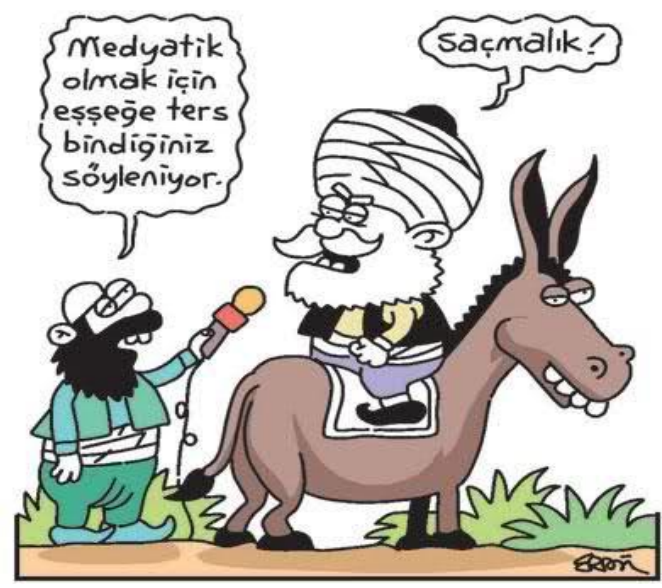

Karikatür 4

\footnotetext{
10 Anakroni hakkında detaylı bilgi için bkz. Genette, Gerard (2011). Anlatının Söylemi: Yöntem Hakkında Bir Deneme (Çev.: F. Burak Aydar), İstanbul: Boğaziçi Üniversitesi Yayınevi.
} 
Nasreddin Hoca'nın fikralarından hareketle onu yumurta satıcısı, balıkçı, pazarcı, bakkal, zeytin satıcısı, iplik satıcısı gibi birçok mesleği icra ederken görmek mümkündür (Sakaoğlu ve Alptekin, 2014: 62). Karikatür 3'te Hoca'nın geçimini komedyenlik/fikra oyunculuğu yaparak sağladığı bir kurgu oluşturulmuş ve "oynadığı fikralar"dan büyük paralar kazandığı ironisi yapılmıştır. Cem Y1lmaz'ın gösterilerinde, sahneye çıkarak çok büyük paralar kazandığ hakkında yaptığ ironilerle ilişkilendirilen bu durum, karikatüre modern çağ vasıtalarından otomobilin de eklenmesiyle ironik ve anakronik bir bağlamda karikatürize edilmiştir. "Sahneye çıkma/mizahı satma" olgusunun işlendiği karikatür 1'de de durum benzerdir. Aynı şekilde karikatür 4 ve 5'te de karikatür 1 ve 3 'teki şöhret olma durumu resmedilmiştir. Karikatüristler Hoca'yı şöhretle ilişkilendirirken, onun eşeğe ters binme (Türkmen, 2013: 119; Sakaoğlu ve Alptekin, 2014: 227; Koz, 2015: 77) detayını 3, 4 ve 5 numaralı karikatürlere eklemeyi unutmamışlardır. Hoca şöhret de olsa, özü aynıdır.

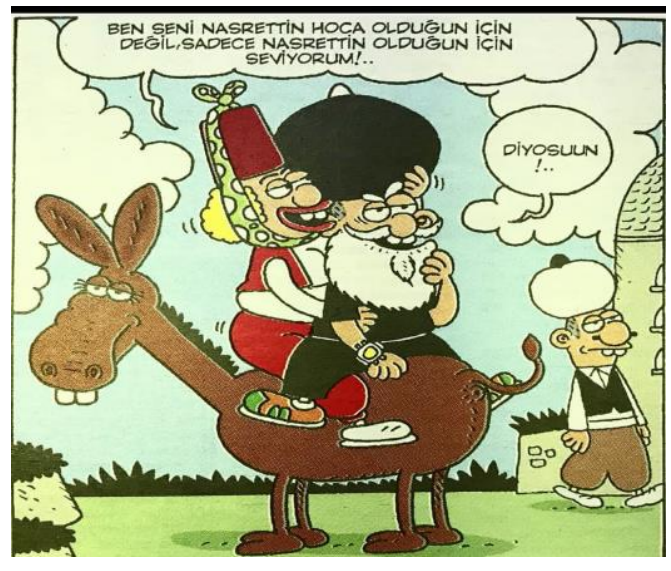

Karikatür 5

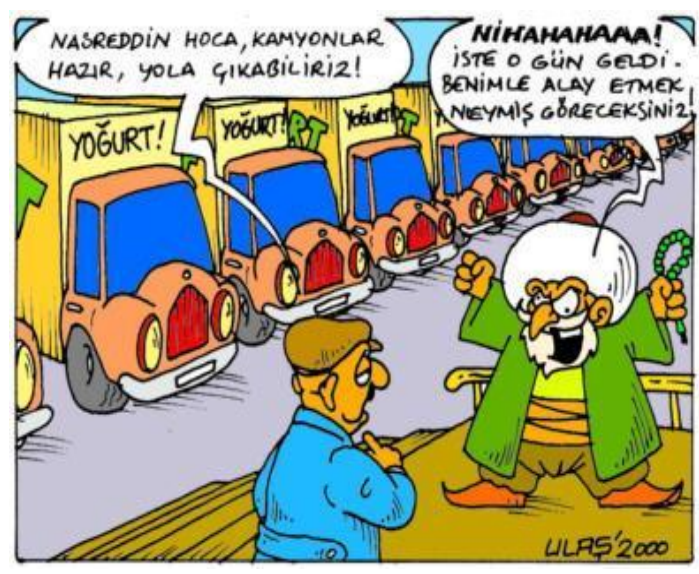

Karikatür 6

Kabalık ve çarpıtma, karikatür yoluyla karakteri abartma, Nietzsche 'ye göre enerjik bir ruhsal yaşamın ve estetik bir yaşamın özünü temsil eder. İkisi arasında güçlü bir bağ kurulabilir (Sanders, 2001: 281). Karikatür 6'da Hoca'nın aşırı hırslı ve biraz da mübalağalı çizimi, "Ya Tutarsa? (Sakaoğlu ve Alptekin, 2014: 232)"fikrasının devamı niteliğindedir. Fıkrayı devam ettiren karikatürist, Hoca'yı, göle maya çalmaya çalışırken kendisiyle alay edenlerden intikamını almış olarak resmetmektedir. Modern çağda tasavvur edilen Hoca, kendi devrine ait bir kılık kıyafetle karşımıza çıkmaktadır.

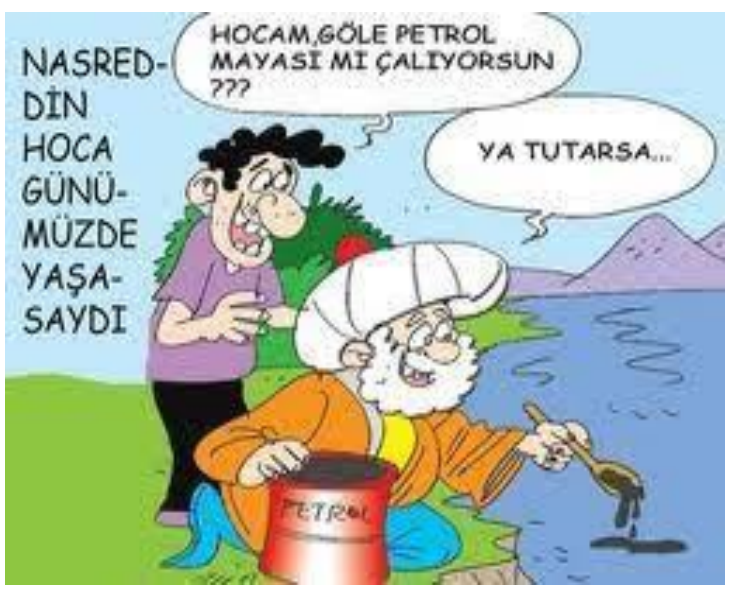

Karikatür 7

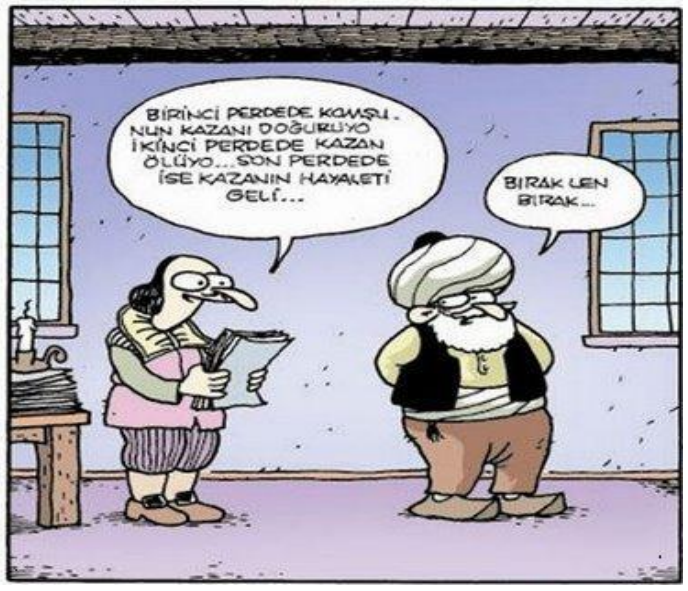

Karikatür 8

Karikatür 7'de yine modern çağda resmedilen Hoca, göle yoğurt mayası çaldığı zamanlardan petrol çaldığı zamanlara nakledilerek "Nasreddin Hoca günümüzde yaşasaydı nasıl olurdu?" sorusu, 
karikatürle cevaplanmaktadır. Karikatür 8'de ise Hoca, Şekspir (Shakespeare)'in çağdaşı olarak karikatürize edilmiştir. Fıkraların bir kısmında Timur'un çağdaşı olarak anlatılan (Sakaoğlu ve Alptekin, 2014: 238-244) Hoca, karikatüristin hayal dünyasında ayağında çarık, belinde kuşağıyla Şekspir (Shakespeare)'in çağdaşı olarak tasavvur edilmiştir.

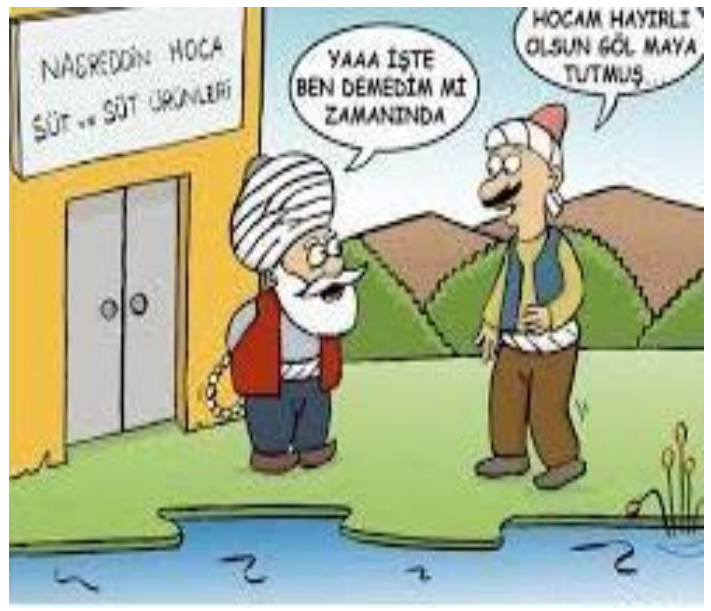

Karikatür 9

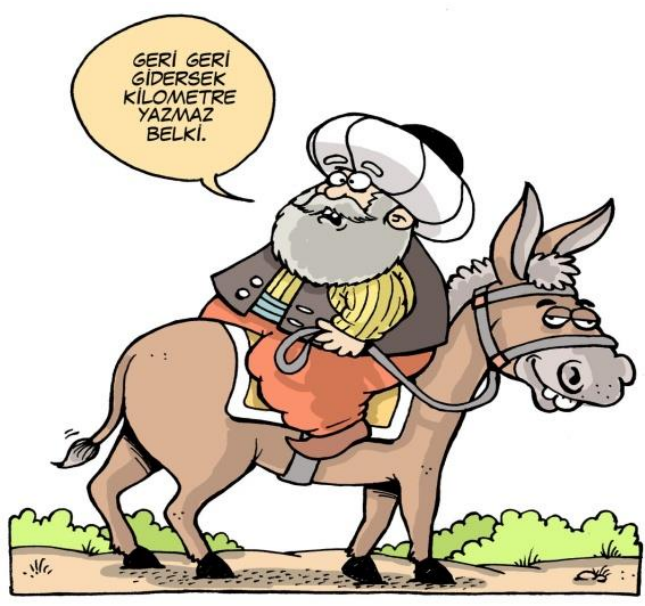

Karikatür 10

Karikatür 9'da da yine Nasreddin Hoca'nın "Ya Tutarsa?" fikrasına atıfta bulunulmuștur. Modern bir tesisin önünde resmedilen Hoca, daha önce göle maya çalarken kendisine "Hocam göl hiç maya tutar mı?" sorusunu soran kişiyle diyalog halindedir. Karikatür 10'da ise Hoca'nın eşeğe ters binmesi günümüz otomobilleriyle ilgili kilometre hesabına atıfta bulunmaktadır. $\mathrm{Bu}$ anakroniyle günümüz anlayışlarından biri Hoca'nın devrine taşınmıştır. Bu anakroniler vasıtasıyla Hoca geçmiş veya gelecek unsurlarıyla buluşturularak gelenek icat edilmiştir.

\section{Fıkraları Devam Ettirmek Marifetiyle Geleneğin İcadı}

Tespit edilen karikatürlerden bir kısmında, Nasreddin Hoca'ya isnat edilen fikralardan bazıları karikatüristlerin hayal dünyasından hareketle devam ettirilmektedir. Raymond'a göre gelenek, eylemde, bir "yeniden üretim" sürecidir (1993: 184). Karikatür sanatçıları, gelenekte var olan birçok unsuru ele alarak bir "yeniden üretim" süreci meydana getirirler. Karikatüristler Nasreddin Hoca fıkralarından yola çıkarak bir kısım fikraları devam ettirme yoluna gitmişlerdir. "Fıkra devam etseydi ne olurdu?" sorusuna karikatüristlerin hayal dünyasından cevap veren bu karikatürler "yeniden üretim" ve "geleneğin icadı" süreçlerini bünyesinde barındırmaktadır.

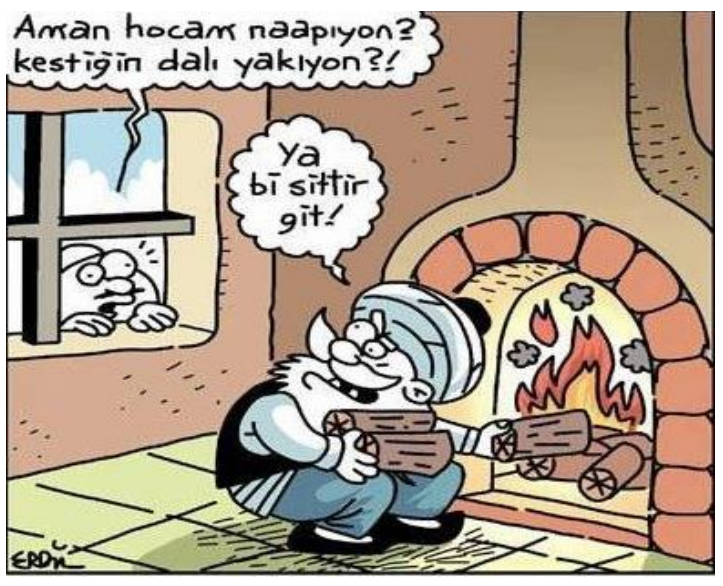

Karikatür 11

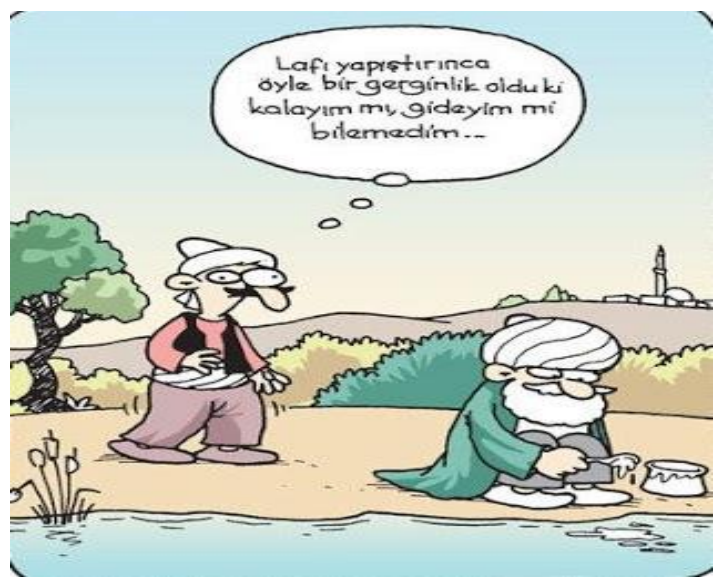

Karikatür 12 
Karikatür 11'de, Nasreddin Hoca'nın bindiği dalı kesmesini anlatan fikra (Koz, 2015: 51; Türkmen, 2013: 101) karikatür yoluyla devam ettirilmiştir. Karikatür 12'de ise Nasreddin Hoca'nın kendisine "Hocam göl hiç maya tutar mı?" diyen kişiye verdiği cevaptan sonrası tasavvur edilmiştir. "Hoca da durur mu? Yapıştırmış cevabı!" sözüne ilintilendirilen karikatürde fıkra, Hoca'nın muhatap olduğu kişi gözünden değerlendirilmiştir.

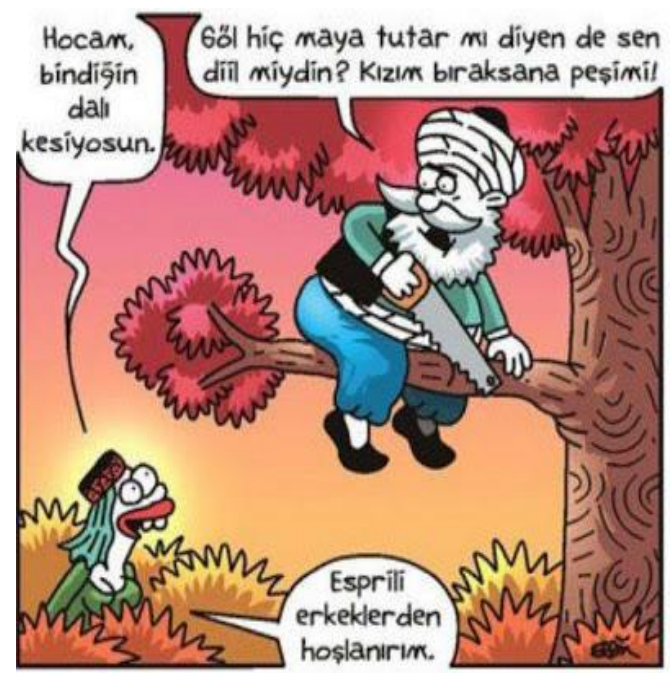

Karikatür 13

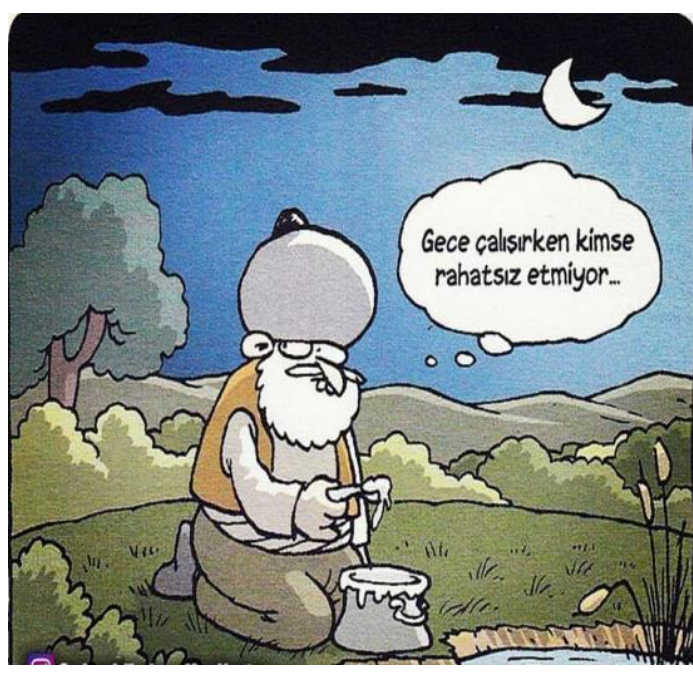

Karikatür 14

Karikatür 13'te iki fikranın konuları harmanlanarak yeni bir fikra meydana getirilmekle beraber, aynı zamanda Hoca'nın bindiği dalı kestiği fıkra devam ettirilmiştir. Bunun yanı sıra günümüzün "kadınlar esprili erkeklerden hoşlanır" şeklindeki klişesi de karikatüre dâhil edilmiştir. Karikatür 14'te ise "göl hiç maya tutar mı?" sorusundan bunalan ve bu yüzden göle maya çalma işini gece gerçekleştiren bir Hoca portresi çizilmiştir.

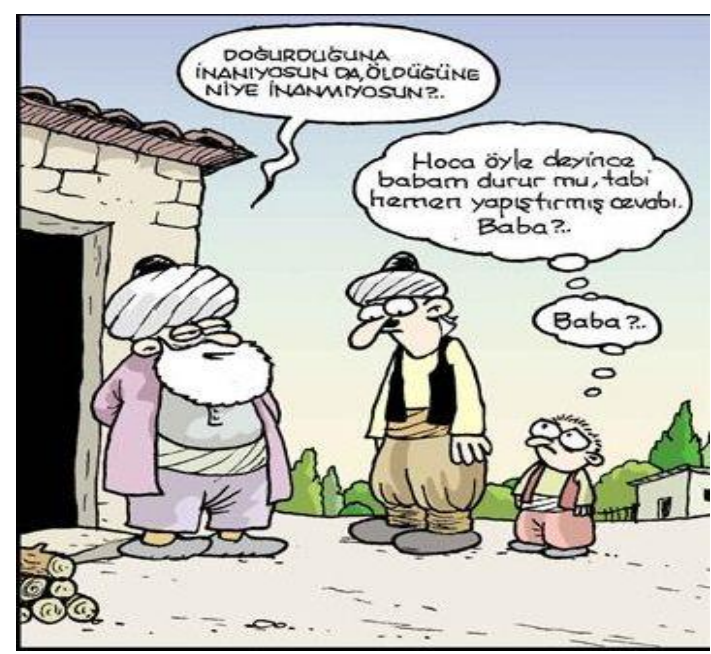

Karikatür 15

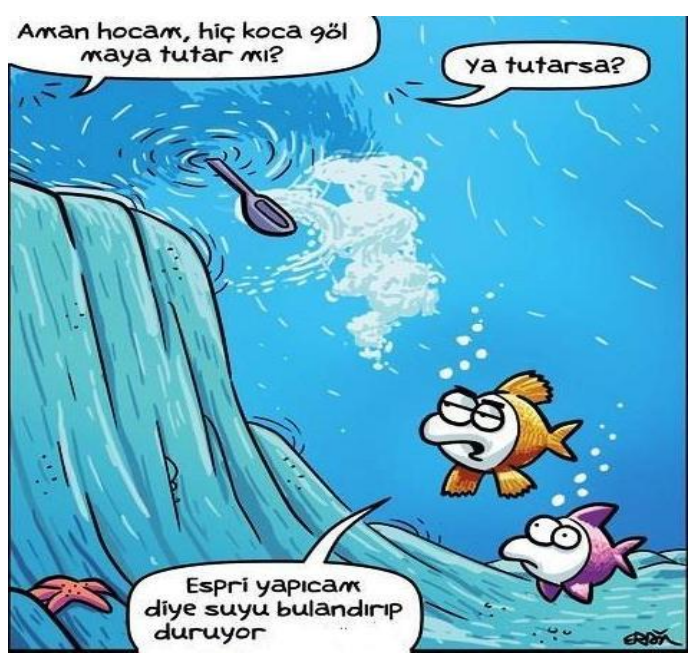

Karikatür 16

Karikatür 15, tıpkı karikatür 12'deki gibi, Hoca'nın muhatap olduğu kimselerin gözünden çizilmiştir. Babası, Hoca'nın söylediklerinin altında kalan küçük çocuk, yine Hoca'ya atfedilen "Hoca da durur mu? Yapıştırmış cevabı." kalıbından hareket babasının Hoca'ya cevap verip, altta 
kalmamasını ummaktadır. Karikatür 16 ise Hoca'nın maya çaldığı göldeki balıkların, karikatüre dâhil edilmesiyle ortaya çıkmış ve fikra devam ettirilmiştir.

\section{Fıkranın Olay Seyrinin Değiştirilmesi Vasıtasıyla Geleneğin İcadı}

Raymond, geleneğin çözümlemede bir zorunluluk olarak değil, arzu edilen bir süreklilik barındırdığı ve geçmişin anlamlı bulunmuş ve yeniden yaşaması istenen öğelerinin tekrar tekrar seçilmesi olduğunu belirtmektedir (1993: 187). Dahası, birçok özelliğiyle kültür, aslında bir "yeniden üretim" tarzıdır ( Raymond, 1993: 184). Bu bakımdan karikatüristler geleneği icat ederken, geçmişin anlamlı buldukları parçalarını seçerek yeniden üretim süreçlerine dâhil etmektedirler. Böylece ortaya çıkan eser, hem geçmişe bir "atıf” hem de bugüne "yeni bir bakış" niteliği taşımaktadır. Bunun yanı sıra bu süreçler sonucu ortaya çıkan eser hem eski hem de yenidir.

Karikatür 17 ve 18'de karikatüristler Hoca'nın bindiği dalı kestiği fikradan ilham almışlardır (Türkmen, 2013: 101; Sakaoğlu ve Alptekin, 2014: 222-223; Koz, 2015: 51). Karikatür 17'de genellikle ebeveynlerin, büyük çocukları bisiklet sürerken onlara hitaben "in de biraz kardeşin binsin" ya da büyük kardeş bir oyuncakla oynarken söyledikleri "bırak da biraz kardeşin oynasın" olgusu, Hoca'nın fikrasıyla birleştirilerek ironik bir karikatür ortaya çıkarılmıştır. Karikatür 18 'de ise Hoca'nın bindiği dalı kesmesi hadisesi, Hoca'nın eşekten düştüğü fıkra (Köprülü, 2004: 160-161; Türkmen, 2013: 188) ile birleştirilmiştir. Bununla beraber Hoca'nın bindiği dalı kestiğini söyleyen kişinin yerini bir sincap almış ve sincap, kendisinin de üzerinde durduğu dalı kestiği için Hoca'ya sitem etmektedir.

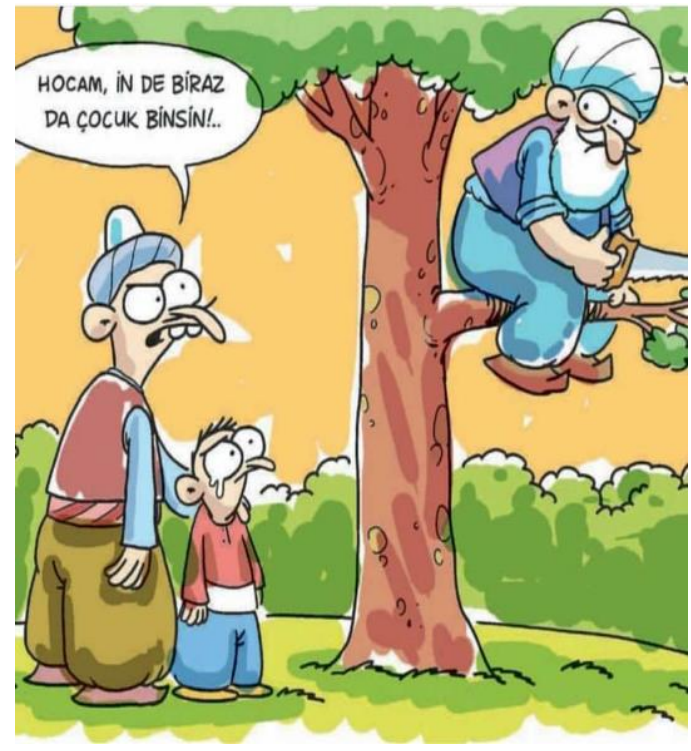

Karikatür 17

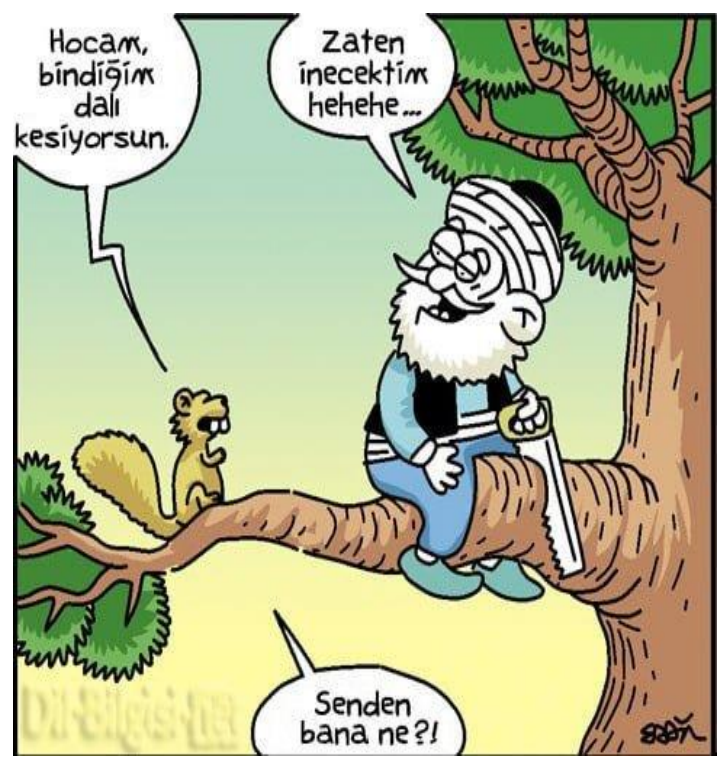

Karikatür 18

Karikatürlerde hayvanların ve cansız varlıkların konuşturulması oldukça sık bir şekilde karşımıza çıkmaktadır. Bu durum bir bakıma fablların günümüz karikatürlerinde devam ettirilmesi gibidir. Karikatür 19'da bir kişinin fikradaki gibi göle maya çalan Hoca'yı uyarmak isterken araya giren talihsiz bir kuş ele alınırken bir sonraki karikatürde, Hoca'nın komşusundan aldığı kazanın doğurduğu fikra (Köprülü, 2004: 77; Türkmen, 2013: 94-95; Sakaoğlu ve Alptekin, 2014: 218; Koz, 2015: 43) ele alınırken güldürü öğesi bir kazanın konuşması üzerinden sağlanmıştır. 


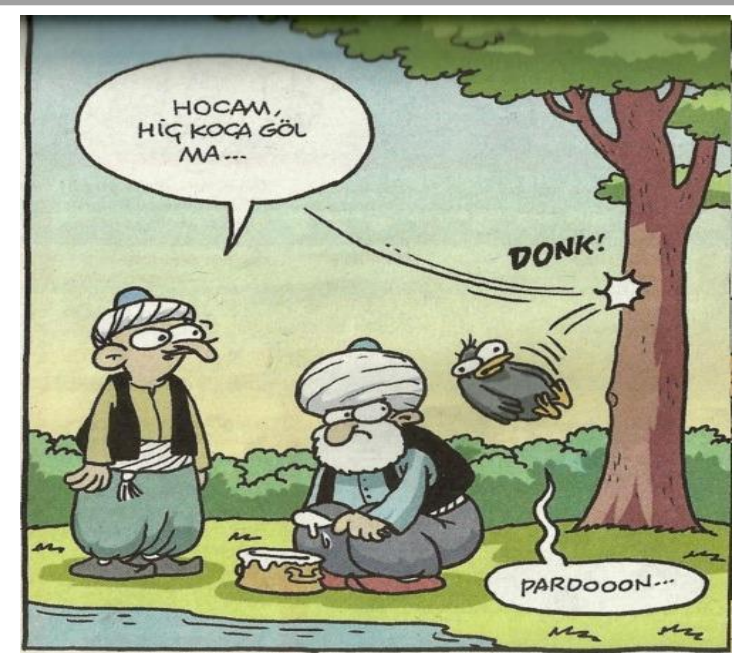

Karikatür 19

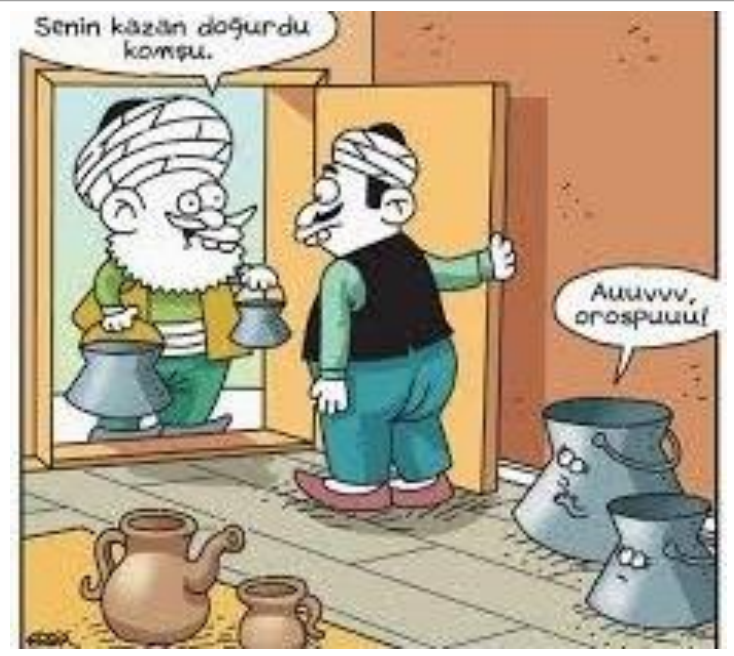

Karikatür 20

Karikatür 21 ve 22 de fikraların değiştirilip dönüştürülerek karikatüristin aklındaki mizahî anlayışa uyarlanması durumuna örnek olarak verilebilir. Karikatür 21'de Hoca'ya atfedilen "kazan doğurdu" fikrası, mizahın temel unsurlarından biri olan "yanlış anlaşılma" durumu üzerine inşa edilmiş̧ir. Bir sonraki karikatürde ise fikrada kazanın ödünç alındığı komşu "Hoca'dan daha uyanık çıkarsa ne olur?" sorusu çevresinde bir anlatı meydana getirilmiştir. Bu karikatürlede, fıkraların ana olay örgülerinden esinlenilmiş ancak olay örgüsü tümden değiştirilerek "gelenek icat edilmiş" ve yeni fikralar ortaya konulmuştur.

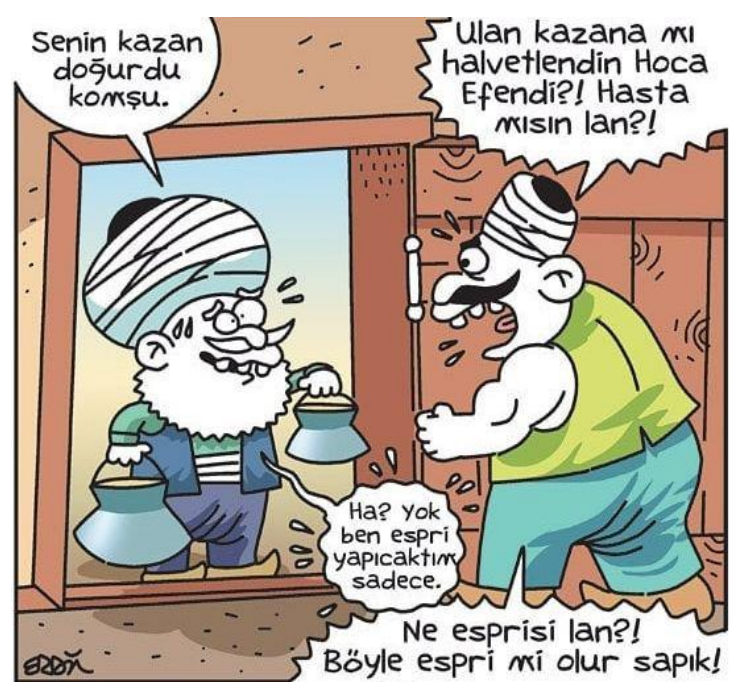

Karikatür 21

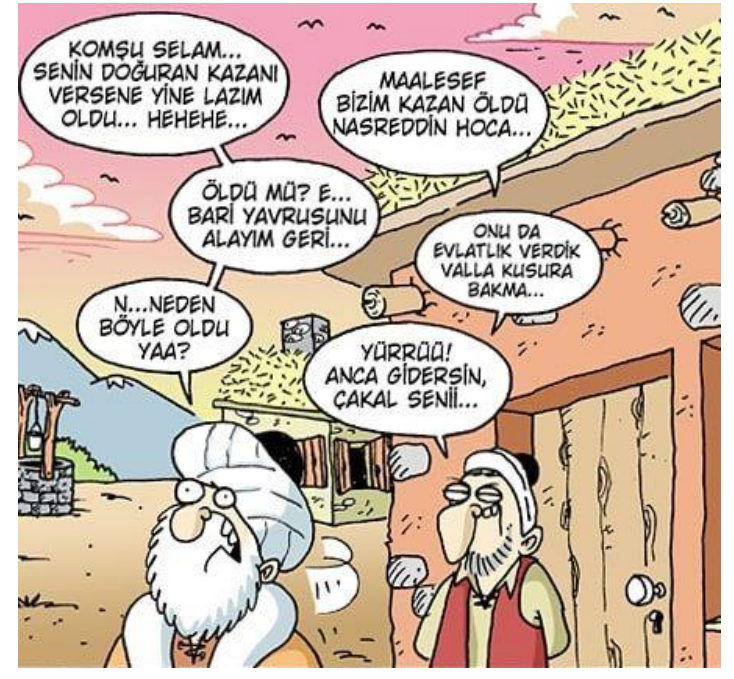

Karikatür 22

Karikatür 23, bir anakroni ile günümüz unsurlarından biri olan "dublör" fikraya dahil edilmiştir. $\mathrm{Bu}$ şekilde fikra, sözlü kültürdeki veya yazıya geçirilmiş halinden başka bir yöne evrilmiştir. Bir sonraki karikatürde ise Hoca, kendi silahı olan hazırcevaplık ile vurulmaktadır. 


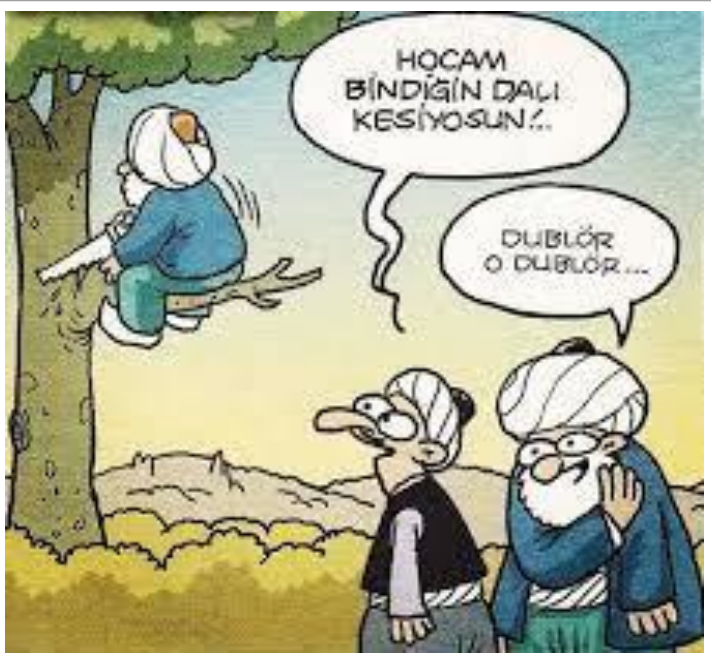

Karikatür 23

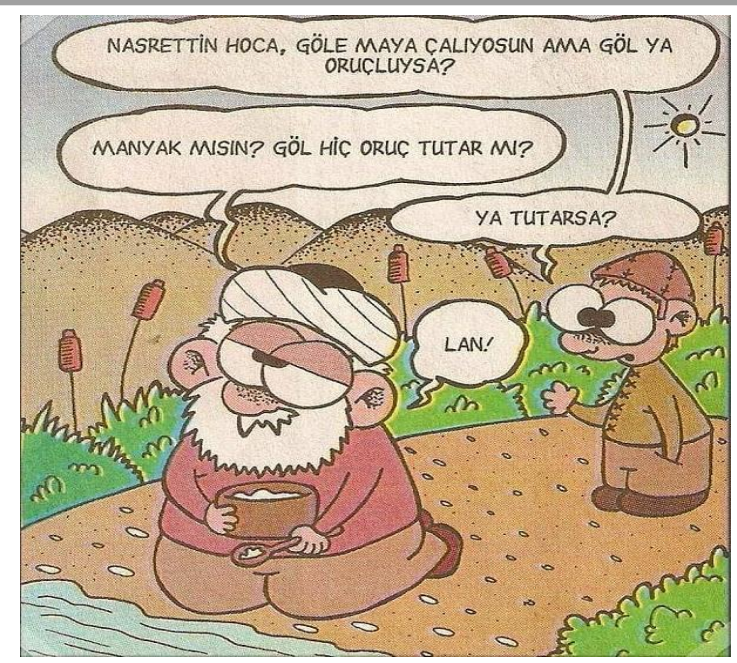

Karikatür 24

\section{Geleneğin Gücünü Vurgulayan Karikatürler}

Gelenek, toplumsal etkisini, varlığını ve gücünü geçmişten alan, bugün için bir şeyler söylerken geleceğe dair yol, toplum hayatının olmazsa olmazlarındandır. Shils'in deyimiyle gelenek, şimdideki geçmiştir ve şimdinin, herhangi bir yeniliği kadar önemli bir parçasıdır. Gelenek, tevarüs edilen yani miras bırakılan her türlü unsuru bünyesinde barındırır. Binaları, abideleri, bahçeleri, heykelleri, resimleri, kitapları, alet ve makineleri içine alır. Yani belirli bir zamanın toplumunun sahip olduğu her şey bu geleneğin içerisindedir. Homeros'un "İlyada"sı bir "traditum" yani gelenektir (2003, 110-111). Bu bakımdan Nasreddin Hoca fikraları da bir "traditum"dur. Hem geçmişe dair her şeyi bünyesinde barındırır hem de bugün için önemli bir unsurdur. Bununla beraber Hoca etrafında gelişen fikra geleneği gerek doğal gerekse icat edilmiş olsun, özünü her zaman Türk mizah kültürünün en önemli yansımalarını barındırmaktadır. Nasreddin Hoca çevresinde gelişen fikralar ve günümüzdeki karikatürler, doğal veya icat edilmiş bir geleneğin parçaları olarak güçlüdür ve toplum üzerinde etki sahibidir. Öyle ki bu güç ve etki karikatürlerde bile kendine yer bulmuştur.

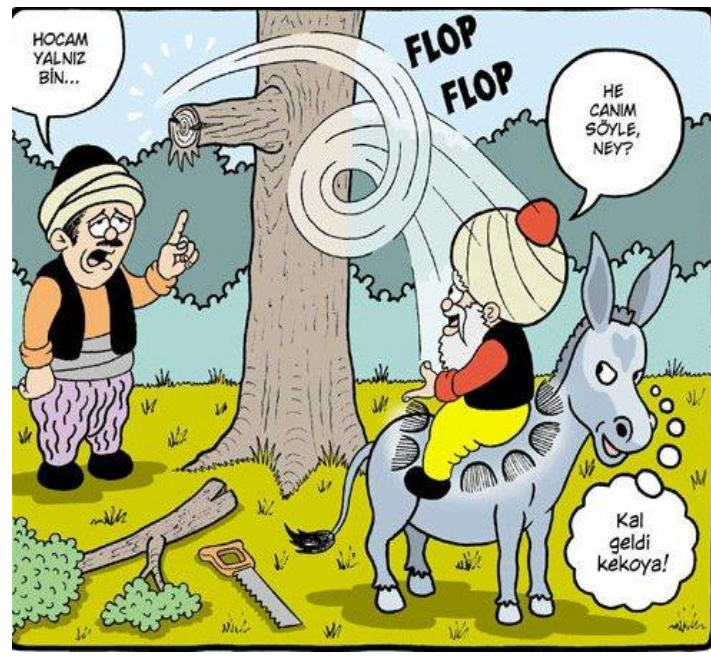

Karikatür 25

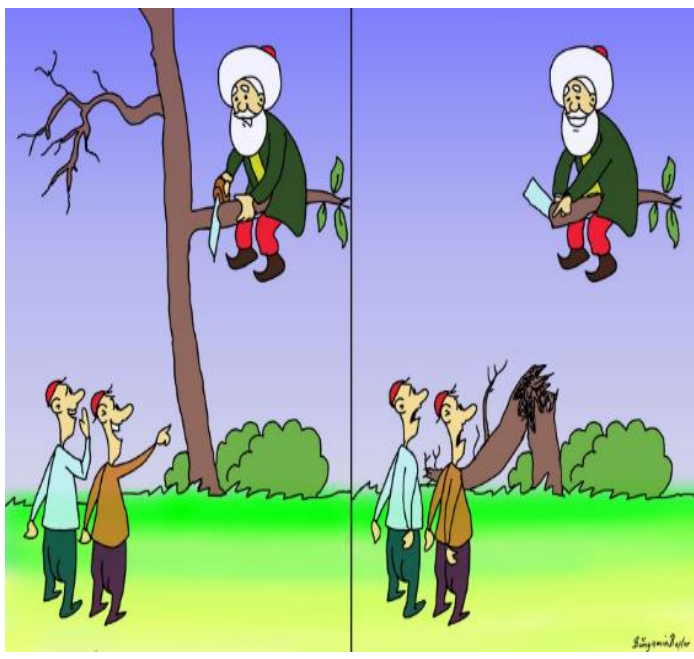

Karikatür 26

İcat edilen her gelenek gücünü geçmişte var olmuş bir doğal gelenekten alır. Bu sebeple icat edilmiş gelenekler doğal gelenekleri desteklerken doğal gelenekler de icat edilmiş geleneklere 
meşruiyet gücü kazandırır. Karikatür 25'te karikatürist, kendini Hoca'dan daha akıllı sayan kişiyi, Hoca'nın ve dolayısıyla geleneğin gücünü kullanarak adeta ters köşe etmiştir. Yine karikatür 26' da da Hoca'ya bindiği dalı kesiyor diye gülenler, ağacın devrilip Hoca'nın havada kaldığını gördükten sonra şaşkınlık içinde kalmıştır. Gelenek güçlüdür ve her daim süreklilik arz edecek bir yol bulmaktadır.

\section{Sonuç}

Nasreddin Hoca Türk mizahının, dünya görüşünün ve yaşam tarzının en önemli unsurlarından biridir. Hoca'nın fikralardaki meziyetlerinin çokluğu, hazırcevaplığı, akılcılığı, nükteli kişiliği ve çok yönlülüğü, geçmişte olduğu gibi bugün de hem Türk insanına hem de dünyaya birtakım mesajlar vermeye devam etmektedir. Hoca'nın çevresinde gelişen fikra geleneği birçok sanat eserine kaynaklık etmekle beraber geleneğin yeniden icat edilmesi yoluyla yeni formlara bürünmektedir.

Nasreddin Hoca'nın, sadece yaşadığı dönemi veya toplumu değil, zamanının ötesine ulaşabilen bilgeliği ve dünyaya yayılmış namı, günümüz ve hatta gelecek için de kapsayıcılık arz etmekte ve insanlığa yol göstermektedir. Karikatüristler Türk mizahının en önemli temsilcilerinden biri olan Nasreddin Hoca'yı büyük bir önemle ve sıklıkla eserlerinde yansıtmakta ve günümüz dünyasında yeni Nasreddin Hoca fikraları meydana getirmektedirler.

$\mathrm{Bu}$ çalışmada Nasreddin Hoca fikralarından hareketle meydana getirilmiş Özer Aydoğan, Serkan Altuniğne, Selçuk Erdem ve Gürcan Yurt gibi birçok karikatüristin kaleminden çıkan 26 karikatür, "anakronizm vasıtasıyla geleneğin icadı, fikraları devam ettirmek vasıtasıyla geleneğin icadı, fikranın olay seyrinin değiştirilmesi vasitasıyla geleneğin icadı, geleneğin gücünü vurgulayan çizgiler" bakımından incelenmiştir. Hoca'nın etrafında gelişen fıkra geleneğinin günümüzde karikatüristlerce "geleneğin icat edilmesi" sürecine tabi tutularak yeni fikraları meydana getirmesi, yeni nesilleri etkilemesi ve yeni bir Hoca imajı çizmesi açısından dikkat çekicidir. Hoca'ya atfedilen karikatürlerin özellikle değiştirilip, dönüştürülerek yeni mizahî unsurlar ve yorumlar oluşturması, günümüz insanının kafasındaki Hoca tiplemesinin, yeni mecralara genişlediğini göstermek bakımından da önemlidir. Hoca'ya atfedilen fikraların karikatürlerdeki yeni halleri veya bu fikralardan esinlenerek oluşturulan karikatürler bir bakıma Nasreddin Hoca çevresinde "yaşayan bir fikra geleneği”" oluşturmakla beraber, yeni nesillerin ilgisini çekecek "yeni bir sözlü kültür" oluşturduğu muhakkaktır.

Karikatüristlerin sanatsal tutumları sonucunda, Nasreddin Hoca'nın hem gelenekten gelen hem de geleneğin izini barındırmak suretiyle yeni bir gelenek meydana getiren karikatürleri, günümüz görsellik çağında önemli bir yer tutmaktadır. Hoca'ya atfedilen fikraların bu şekilde işlenmesi yoluyla oluşturulacak karikatürler ve yeni fikraların geleneği desteklediği, yeniden gündeme getirdiği ve değiştirerek geleneği icat ettiği görülmektedir. Bu bakımdan karikatürler üzerinden yapılacak incelemeler, günümüz sosyolojik, kültürel ve yeni geleneksel hayatına dair önemli cevaplar verecektir.

\section{KAYNAKÇA}

Atsı,, H. N. (2014). Türk tarihinde meseleler. Ankara: Ötüken Neşriyat.

Balcıŏlu, S. (1976). 50 yılın Türk mizah ve karikatürü. İstanbul: Türkiye İş Bankası Kültür Yayınları.

Henry, B. (2014). Gülme gülüncün anlamı üzerine deneme (Çev.: Devrim Çetinkasap). İstanbul: İş Bankası Kültür Yayınları.

Boratav, P. N. (2007). Nasreddin hoca. İstanbul: Kırmızı Yayınları.

Genette, G. (2011). Anlatının söylemi: yöntem hakkında bir deneme (Çev.: F. Burak Aydar), İstanbul: Boğaziçi Üniversitesi Yayınevi.

Hobsbawm, E. ve Ranger, T. (2006). Geleneğin icadı (Çev.: M. Murat Şahin). İstanbul: Agora Kitaplı̆̆ 1 (2006). 
Kızıldağ, H. (2016). Anakronik bir kahraman: Keloğlan aramızda. The Journal of Academic Social Science Studies-JASSS (53): 447-458.

Kızıldağ, H. ve Kızıldağ, F. (2018). İcradan karikatüre: âşıklık geleneği. 4. Uluslararası Filoloji Seтроzуити, Alaaddin Keykubat Üniversitesi Alanya: 269-288

Koestler, A. (1997). Mizah yaratma eylemi (Çev.: Sevinç Kabakçığlu-Özcan Kabakçığlu). İstanbul, İris Yayınları.

Köprülü, M. F. (2004). Nasrettin hoca. Ankara: Akçağ Yayınları.

Letâ'if Nasreddin hoca fikralarının ilk baskısı (2015). Haz.: M. Sabri Koz. İstanbul: Büyüyenay Yayınları.

Öngören, F. (1998). Cumhuriyetin 75. yılında Türk mizahı ve hicvi. İstanbul: İş Bankası Kültür Yayınları.

Özdemir, N. (2012). Medya kültür ve edebiyat. Ankara: Grafiker Yayınlar1.

Sakaoğlu, S. ve Alptekin, A. B. (2014). Nasreddin hoca. Ankara: Atatürk Kültür Merkezi Yayınları.

Sanders, B. (2001). Kahkahanın zaferi (Çev.: Kemal Atakay). İstanbul: Ayrıntı Yayınları.

Seyyid Burhaneddin Çelebi (2013). Nasreddin hoca latifeleri (Burhaniye Tercümesi) (Haz.: Fikret Türkmen). İstanbul: Büyüyenay Yayınları.

Shils, E. (2003). Gelenek (Çev.: Hüsamettin Arslan). Doğu Batı (25): 101-131.

Şenocak, E. (2017). Ironik yaşamda sonsuza yürüyen kahraman Nasreddin hoca. Ankara: Akçă̆ Yayınları.

Williams, R. (1993). Kültür (Çev.: Suavi Aydın). Ankara: İmge Kitabevi.

\section{İnternet Kaynakları}

Karikatür 1 (Erişim Tarihi: 12.07.2019)

http://nasrettin-hoca.blogcu.com/

Karikatür 2 (Erişim Tarihi: 17.09.2019)

http://karikaturleriniz.blogspot.com/2013/04/nasreddin-hoca-kugu.html

Karikatür 3 (Erişim Tarihi: 12.07.2019)

https://tr.pinterest.com/pin/553520610431403979/?lp=true

Karikatür 4 (Erişim Tarihi: 12.07.2019)

http://www.cizgidiyari.com/forum/karikaturler/61868-nasreddin-hoca-karikaturleri.html

Karikatür 5 (Erişim Tarihi: 12.07.2019)

http://www.cizgidiyari.com/forum/karikaturler/61868-nasreddin-hoca-karikaturleri.html

Karikatür 6 (Erişim Tarihi: 17.09.2019)

http://karikaturborsasi.blogspot.com/2013/04/nasrediin-hoca-karikaturleri-iste-ogun.html

Karikatür 7 (Erişim Tarihi: 12.07.2019)

http://karikaturborsasi.blogspot.com/2013/03/nasreddin-hoca-karikaturleri-ya-tutarsa.html

Karikatür 8 (Erişim Tarihi: 15.09.2019) 
http://nasrettin-hoca.blogcu.com/

Karikatür 9 (Erişim Tarihi: 17.09.2019)

http://nasrettin-hoca.blogcu.com/

Karikatür 10 (Erişim Tarihi: 12.07.2019)

https://twitter.com/onurkaradurmus/status/904647659482480641

Karikatür 11 (Erişim Tarihi: 17.09.2019)

http://karikaturborsasi.blogspot.com/2013/05/kestigin-dal-yakyon.html

Karikatür 12 (Erişim Tarihi: 17.09.2019)

http://karikaturborsasi.blogspot.com/2013/03/nasreddin-hoca-karikaturleri-gerginlik.html

Karikatür 13 (Erişim Tarihi: 17.09.2019)

http://karikaturborsasi.blogspot.com/2013/03/nasreddin-hoca-karikatur-esprili.html

Karikatür 14 (Erişim Tarihi: 12.07.2019) https://pikdo.net/p/karikaturlubisey/1759710995766657090_543988342355

Karikatür 15 (Erişim Tarihi: 17.09.2019)

https://www.karikaturu.com/evlat-hocayla-saka-olmaz.html

Karikatür 18 (Erişim Tarihi: 12.07.2019)

https://www.dilbilgisi.net/eglence/karikaturler/deyim-karikaturleri/

Karikatür 19 (Erişim Tarihi: 13.07.2019) https://karikaturler.tumblr.com/post/19116821398/amp

Karikatür 20 (Erişim Tarihi: 12.07.2019)

http://karikaturborsasi.blogspot.com/2014/06/nasreddin-hoca-karikaturleri-kazan.html

Karikatür 21 (Erişim Tarihi: 13.07.2019) https://pikdo.net/p/cartoon.cu/1991621299236854965_6081029818

Karikatür 22 (Erișim Tarihi: 18.07.2019)

https://deskgram.cc/explore/tags/Kazando\%C4\%9Furdu

Karikatür 23 (Erişim Tarihi: 12.07.2019)

https://www.igdownloader.net/tag/Nasrettin

Karikatür 24 (Erişim Tarihi: 17.09.2019)

https://eodev.com/gorev/3134444

Karikatür 25 (Erişim Tarihi: 17.09.2019)

http://www.karikatursepeti.xyz/nasrettin-hoca-karikaturleri/

Karikatür 26 (Erişim Tarihi: 12.07.2019)

http://altinotu.blogspot.com/2016/06/nasrettin-hoca-bindigi-dali-kesiyor.html 